\title{
A noção de mobilização na associação da Física a objetos tecnológicos contemporâneos
}

\section{The notion of mobilization in the association of Physics to contemporary technological objects}

\author{
André Coelho da Silva ${ }^{1}$ - Maria José Pereira Monteiro de Almeida ${ }^{2}$
}

\begin{abstract}
Resumo: Assumindo ser interessante, no ensino de Física, a explicitação de utilidades práticas ou possíveis relações entre conteúdos da física e aspectos da cotidianidade, procuramos esboçar respostas à seguinte questão: a explicitação de relações da física com aspectos de objetos tecnológicos contemporâneos pode mobilizar estudantes do Ensino Médio para o estudo dessa disciplina? Pautados na noção de mobilização conforme proposta por Bernard Charlot e em noções da Análise de Discurso iniciada por Michel Pêcheux, analisamos informações coletadas junto a estudantes a partir de atividades envolvendo a leitura de textos de divulgação científica e respostas a questionários contendo questões abertas. As análises realizadas sugerem que explicitar relações entre conteúdos da física e aspectos associados à produção e ao funcionamento de objetos tecnológicos contemporâneos, tais como o telefone, o computador e os aparelhos de raios-X e de ressonância magnética, pode funcionar como móbile da mobilização em relação ao estudo da física.
\end{abstract}

Palavras-chave: Ensino de Física. Ensino médio. Objetos tecnológicos. Mobilização.

\begin{abstract}
Assuming that Physics education has interesting explicit practical activities or possible relationships between physics content and aspects of everydayness, we tried to outline answers to the following question: Can the explicitness of relationships between physics and aspects of contemporary technological objects can mobilize high school students for the study of this discipline? Guided by the notion of mobilization as proposed by Bernard Charlot and by notions of Discourse Analysis initiated by Michel Pêcheux, we analyze information collected from student activities involving the reading of scientific dissemination texts and responses to questionnaires containing open questions. The analyses suggest that explicit relationships between physics content and aspects associated with the production and functioning of contemporary technological objects, such as the telephone, computer, X-ray and magnetic resonance apparatus, can function as vehicle of mobilization in respect of the study of physics.
\end{abstract}

Keywords: Physics teaching. High School. Technological objects. Mobilization.

\footnotetext{
${ }^{1}$ Instituto Federal de Educação, Ciência e Tecnologia de São Paulo (IFSP), Avenida João Olímpio de Oliveira, 1561, Vila Asem, CEP 18202-000, Itapetininga, SP, Brasil. E-mail: <andco_8@yahoo.com.br>

${ }^{2}$ Departamento de Ensino e Práticas Culturais, Faculdade de Educação, Universidade Estadual de Campinas (UNICAMP), Campinas, SP, Brasil.
} 


\section{Introdução}

Ao dialogar com as constatações de muitos professores, os quais comumente afirmam que o nível de participação de seus alunos nas atividades é insatisfatório, Dayrell (1996) sugere a importância de se pensar qual é o significado da escola e das aulas para esses jovens. Nas palavras do autor: "Diante da aula, a pergunta imediata poderia ser: quais são os objetivos desta unidade? Qual a relação que existe com a realidade dos alunos? O que e em que este tema acrescenta algo ou é importante para cada um deles?” (DAYRELL, 1996, p. 155).

De maneira coerente com a consideração de Dayrell (1996), Dias, Barlette e Martins (2009) ressaltam que muitos alunos valorizam o estudo de tópicos que possibilitem estabelecer relações com aspectos do dia a dia. Nesse sentido, afirmam os autores:

Os alunos consideram a aprendizagem de um conteúdo mais interessante e fácil quando este pode ser relacionado diretamente com suas experiências diárias. A "materialidade" do cotidiano funciona como um ponto de partida, uma referência a partir da qual podem começar a pensar em termos mais abstratos. Ao mesmo tempo, a conexão dos conteúdos mais abstratos com situações do dia-a-dia serve também como um fator motivador para a aprendizagem. Diversos autores observam que a possibilidade do aluno relacionar o conteúdo a ser aprendido com a experiência prévia facilita a aprendizagem. (DIAS; BARLETTTE; MARTINS, 2009, p. 113)

Acreditamos que não se trata de defender o conhecimento como um puro e simples meio para entender de forma mais embasada as experiências diárias vivenciadas no mundo material do qual fazemos parte, em uma visão utilitarista acerca do conhecimento. Antes disso, trata-se de entender o conhecimento sob uma perspectiva cultural, ou seja, a aquisição de conhecimento como forma de "autodesenvolvimento", de desenvolvimento cultural. Dessa forma, um entendimento mais embasado das situações, do mundo e de si mesmo seria apenas um efeito (positivo) desse processo.

Zanetic (1989) defendeu, em sua tese de doutorado, que Física também é cultura. Nesse sentido, argumentou que seria interessante apresentar a física escolar como um elemento cultural básico para a compreensão do mundo contemporâneo, isto é, para a compreensão dos fenômenos e dos aparelhos utilizados no cotidiano. Emprestando de Snyders (1988 apud ZANETIC, 1989, p. 35) os conceitos de cultura primeira e cultura elaborada ${ }^{3}$, Zanetic (1989) afirmou, ainda, que defender um ensino de Física mais próximo do dia a dia, da realidade que cerca a maioria dos alunos, não implica uma redução ao nível do senso comum. Diferentemente disso, tratar-se-ia de estabelecer a continuidade necessária à ruptura. Continuidade esta com a cultura primeira que, em geral, não estaria sendo explorada no ensino da Física. Ainda segundo o autor:

\footnotetext{
${ }^{3}$ Cultura primeira: aquela que nasce como decorrência da experiência direta com a vida; Cultura elaborada: aquela que se dirige a todos - as artes, as letras, as ideias políticas, as Ciências. A cultura elaborada completa a "satisfação cultural" para a qual tende a cultura primeira, em um processo de continuidade e ruptura.
} 
Infelizmente um cidadão contemporâneo médio (ou seja, igual a todos nós) é ensinado durante a sua vida escolar que a ciência é uma matéria esotérica, que não tem nada a ver com a vida atual das pessoas, que não faz parte da bagagem cultural. Por outro lado, algo que paradoxalmente passa desapercebido da maioria das pessoas, somos bombardeados pela manipulação ideológica da ciência pelos meios de comunicação: um creme dental testado cientificamente, as desastrosas consequências para o desenvolvimento do país da exiguidade de recursos para as pesquisas científicas, as ciências no vestibular... É tudo uma ficção científica. Ao mesmo tempo nos deparamos com as dificuldades em lidar com informações científicas básicas, como foi o caso do acidente radioativo de Goiânia em 1988. E também há o crescente interesse despertado por livros de divulgação científica que atingem, às vezes, várias edições no nosso mercado editorial. Mas há uma dificuldade muito grande em integrar essa incipiente curiosidade cultural pela ciência e aquilo que se passa na escola. Ou seja, a maioria das pessoas consome ciência enquanto cultura mas, ao mesmo tempo, está alienada de sua presença real no cotidiano. E a forma e o conteúdo da ciência processada na escola reforçam essa condição de distanciamento entre a física escolar e a vida das pessoas, da ausência organizada da ciência na cultura popular. [...] (ZANETIC, 1989, p. 96)

Neste trabalho, consideramos a Física como cultura, assumindo, contudo, que uma cultura é a "soma de diferentes sistemas de classificação e diferentes formações discursivas aos quais a língua recorre a fim de dar significado às coisas" (HALL, 1997, p. 10). Nesse sentido, toda prática social tem uma dimensão cultural, isto é, "cada instituição ou atividade social gera e requer seu próprio universo distinto de significados e práticas - sua própria cultura" (HALL, 1997, p. 13). Dessa maneira, procuramos ressaltar a concepção de que há múltiplas culturas - e não somente "a" cultura (associada à elite).

Ainda nessa perspectiva de pensar elementos culturais associados à física, parecem perder sentido perguntas do tipo: "Por que tenho de aprender isso? Para que me serve aprender isso?”. Aparentemente, ninguém questiona para que serve uma cultura.

Por outro lado, não é comum ou adequado se dispor a realizar alguma atividade sem que seu valor ou utilidade estejam mais ou menos explícitos. Nesse sentido, Fourez (2003, p. 110) afirma que:

[...] os jovens de hoje parece que não aceitam mais se engajar em um processo que se lhes quer impor sem que tenham sido antes convencidos de que esta via é interessante para eles ou para a sociedade. Isto vale para todos os cursos, mas talvez ainda mais para a abstração científica. [...] Muitos jovens de hoje pedem que lhes seja mostrado de início a importância - cultural, social, econômica ou outra - de fazer este desvio. Mas nós, seus professores, estamos prontos e somos capazes de lhes mostrar esta importância? 
Pressupomos que as utilidades são mutáveis e que podem ser produzidas, isto é, que os "bons motivos" para realizar alguma atividade dependem do contexto histórico-cultural e que, certas vezes, não são evidentes ou explícitos. Nesse sentido, acreditamos ser importante tornar explícitas possíveis relações entre os conteúdos da Física e aspectos da cotidianidade. Vale frisar, todavia, que, com isso, não estamos em defesa de um ensino que tenha como base o "mundo dos alunos", convidando-os a continuar com suas representações do senso comum, mas, sim, de mostrar-lhes, como aponta Fourez (2003, p. 120), "que o desvio pelas representações padronizadas das ciências é interessante".

Particularmente no que diz respeito ao ensino de Física e das outras chamadas "ciências da natureza" no Ensino Médio (EM), tendo em vista a forte presença da tecnologia na atual conjuntura sociocultural e o fato de que muitos objetos tecnológicos que utilizamos no dia a dia estão impregnados de pensamento científico (GRANGER, 1994), uma das maneiras de explicitar utilidades práticas e relações entre os conteúdos formais dessas disciplinas e aspectos do mundo observados pelos estudantes parece ser discutir elementos associados à tecnologia, como, por exemplo, o funcionamento de objetos tecnológicos contemporâneos. De fato, em Lima e Rappoport (2009), a primeira autora, professora de Física desse nível de ensino, atribui sua dificuldade em desencadear o interesse de seus estudantes à ausência de explicitação de possíveis relações entre os conteúdos formais da Física e as novas tecnologias: "Eu digo a eles que a Física possibilita entender como funciona 'o Mundo' e eles não concordam. A verdade é que a Física que eu tento ensinar na escola não explica as novas tecnologias” (LIMA; RAPPOPORT, 2009, p. 1).

A fim de caracterizarmos o que estamos entendendo por objetos tecnológicos contemporâneos, apoiamo-nos em Vargas (2003) e em Nascimento, Santos e Nigri (2006).

Vargas (2003) procurou apontar algumas características da ciência básica, da técnica e da tecnologia. A primeira objetivaria conhecer determinado assunto. A técnica estaria mais relacionada a trabalhos manuais e mecânicos. Já a tecnologia seria uma etapa do desenvolvimento técnico, pois utilizaria (e não simplesmente aplicaria) teorias, métodos e processos científicos para a resolução de problemas técnicos. Além disso, segundo o autor, não haveria tecnologia se não houvesse pesquisa tecnológica. Vargas (2003) ressalta ainda dois pontos importantes: a não-neutralidade da ciência e da tecnologia - isto é, elas estariam comprometidas com as condições políticas e econômicas da sociedade - e o fato de que tanto é possível surgir uma aplicação a partir de um conhecimento básico, como uma pesquisa científica a partir de uma solução tecnológica.

Já Nascimento, Santos e Nigri (2006), amparados em Saldaña (1997 apud NASCIMENTO; SANTOS; NIGRI, 2006, p. 55), afirmam que enquanto a técnica visa resolver problemas pontuais do cotidiano, a ciência modeliza o real sem propor, necessariamente, intervenções. A tecnologia, por sua vez, seria uma modernização da técnica e, nesse sentido, romperia com as funções básicas do dia a dia, tendo como pretensão a criação de novos objetos, regras, gestos e, consequentemente, novas necessidades. Segundo os autores: "Encontramos facetas da tecnologia no conjunto de todas as culturas e essas são, em geral, registradas através de objetos pertencentes à cultura material" (NASCIMENTO; SANTOS; NIGRI, 2006, p. 55). Em relação à caracterização do que são objetos, Dagognet (1989 apud NASCIMENTO; SANTOS; NIGRI, 2006, p. 55) toma-os como "coisas" carregadas de subjetividade humana, isto é, "coisas" às quais são atribuídas funções. 
Dito isto, embora reconheçamos a dificuldade em caracterizar o que é um objeto tecnológico contemporâneo, estamos utilizando o termo para designar aparelhos ${ }^{4}$ que desempenham funções elaboradas e cujo funcionamento pode ser explicado a partir de teorias científicas relativamente sofisticadas. Frisamos, contudo, que se trata de uma caracterização bastante subjetiva e dependente dos contextos social e histórico considerados. É difícil caracterizar de maneira objetiva e atemporal o que são "funções elaboradas" e "teorias científicas relativamente sofisticadas". Vale ressaltar, ainda, que acreditamos na não-neutralidade da tecnologia, e que não a pensamos como uma mera aplicação da ciência - tomamos as duas como inter-relacionadas.

Tendo em vista a breve discussão acima realizada, neste trabalho, procuramos esboçar respostas à seguinte questão: a explicitação de relações da Física com aspectos de objetos tecnológicos contemporâneos pode mobilizar estudantes do Ensino Médio pelo estudo dessa disciplina? "Mobilização" entendida, aqui, conforme Charlot (2000) - enquanto alternativa aos conceitos de "motivação" e "interesse":

O conceito de mobilização implica a ideia de movimento. Mobilizar é pôr em movimento; mobilizar-se é pôr-se em movimento. Para insistir nessa dinâmica interna é que utilizamos o termo de "mobilização", de preferência ao de "motivação". A mobilização implica mobilizar-se ("de dentro"), enquanto que a motivação enfatiza o fato de que se é motivado por alguém ou por algo ("de fora"). É verdade que, no fim da análise, esses conceitos convergem: poder-se-ia dizer que eu me mobilizo para alcançar um objetivo que me motiva e que sou motivado por algo que pode mobilizar-me. [...] Mobilizar-se, porém, é também engajar-se em uma atividade originada por móbiles, porque existem "boas razões" para fazê-lo. Interessarão, então, os móbiles da mobilização, o que produz a movimentação, a entrada em atividade. [...] A criança mobiliza-se, em uma atividade, quando investe nela, quando faz uso de si mesma como de um recurso, quando é posta em movimento por móbeis que remetem a um desejo, um sentido, um valor. [...] (CHARLOT, 2000, p. 55, grifo nosso)

Segundo Charlot (2000), educar-se é produzir a si mesmo, apropriando-se do que lhe é exterior com o auxílio da mediação do outro. E, para isso, deve haver mobilização, pois, embora a dimensão sócio-histórica intervenha, a construção de si por si mesmo é interna ao sujeito.

Dessa forma, justifica-se a relevância de estudos acerca da mobilização para aprender; afinal, caso não haja mobilização por parte dos educandos, fica impossibilitada a atuação mediadora dos professores em sala de aula:

[...] Ninguém poderá educar-me se eu não consentir, de alguma maneira, se eu não colaborar; uma educação é impossível, se o sujeito a ser edu-

\footnotetext{
${ }^{4}$ Conjunto de peças, ferramentas, utensílios ou instrumentos, destinado a executar um trabalho ou prestar um serviço - uma das possíveis definições para “aparelho" segundo o dicionário Michaelis (2009).
} 
cado não investe pessoalmente no processo que o educa. Inversamente, porém, eu só posso educar-me numa troca com os outros e com o mundo; a educação é impossível, se a criança não encontra no mundo o que lhe permite construir-se. [...] (CHARLOT, 2000, p. 53-54)

Para esboçarmos respostas à questão proposta neste trabalho, pautados na noção de mobilização proposta por Charlot (2000) e em noções da Análise de Discurso em sua vertente iniciada na França por Michel Pêcheux (1966), analisamos informações coletadas junto a estudantes do EM em três diferentes oportunidades, as quais serão doravante nomeadas de Atividade I, Atividade II e Atividade III.

As três atividades têm em comum o fato de que foram desenvolvidas em sala de aula por meio da leitura individual de textos de divulgação científica entregues aos alunos. As duas primeiras atividades estão relacionadas a tentativas de inserção de tópicos de Física Moderna e Contemporânea (FMC) no EM, conforme sugerido por muitos pesquisadores da área de ensino de Física/Ciências (PEREIRA; OSTERMANN, 2009; SILVA; ALMEIDA, 2011, entre muitos outros). Já a terceira atividade foi desenvolvida tendo em vista os resultados das duas anteriores, entre eles o de que estudantes do EM parecem se interessar pela compreensão de aspectos do funcionamento dos aparelhos de ressonância magnética.

\section{Condições de produção das atividades}

A Atividade I foi desenvolvida no final do ano letivo de 2010 com alunos de duas turmas do terceiro ano do EM diurno de uma escola pública do Estado de São Paulo. A partir de recortes de artigos publicados na revista de divulgação científica "Com Ciência", montamos um texto que visa informar, muito sinteticamente, as origens da Física Quântica (FQ) e qual a sua relevância em termos de aplicações tecnológicas (Anexo A). No total, 25 alunos leram o texto individualmente e responderam a um questionário formulado com cinco questões abertas 5 .

Vale frisar que houve permissão do professor das turmas para a realização da atividade com os alunos, e que o responsável pela solicitação de leitura e aplicação do questionário - primeiro autor deste trabalho - nunca tinha tido contato anterior com as turmas nem era professor da escola. Foi dito, aos alunos, que a atividade não era obrigatória e não valia nenhum tipo de nota. Também foi colocado o compromisso de que, em nenhum momento, seriam identificados os autores das respostas.

O questionário respondido pelos estudantes concomitantemente à leitura do texto continha as seguintes questões: (1) Você já tinha ouvido falar ou lido alguma coisa sobre a teoria quântica? O que e onde?; (2) Se você fosse contar a alguém o que leu nesse texto, o que você contaria?; (3) Que dificuldades você teve na leitura do texto?; (4) Você gostaria de ter aulas sobre a física quântica? Para quê?; (5) Dentre as aplicações da teoria quântica citadas no texto (aparelho de CD, controle remoto, aparelhos de ressonância magnética de hospitais, telefones

\footnotetext{
${ }^{5}$ Estamos considerando como questão aberta aquela que permite a possibilidade de se obter, na resposta, posições/opiniões pessoais.
} 
celulares, laseres, genética molecular, microcomputadores), de qual você preferiria compreender o funcionamento?

A Atividade II foi desenvolvida em abril de 2012, com três turmas do segundo ano do EM diurno de outra escola pública do Estado de São Paulo, sendo que o primeiro autor deste trabalho era professor de Física das turmas. Tratou-se da mesma atividade já mencionada, ou seja, da leitura de um texto (Anexo A) e da aplicação de um questionário composto pelas seguintes questões (a maioria delas idênticas à do questionário da Atividade I): (1) Você já tinha ouvido falar ou lido alguma coisa sobre a teoria quântica? O que e onde?; (2) Se você fosse contar a alguém o que leu nesse texto, o que você contaria?; (3) Que dificuldades você teve na leitura do texto?; (4) Você gostaria de ter aulas sobre a física quântica? Para quê? Por quê?; (5) Dentre os seguintes objetos que foram produzidos a partir de conhecimentos obtidos com a física quântica, de qual ou quais você gostaria de entender o funcionamento: aparelho de CD; aparelho de ressonância magnética; controle remoto; lasers; telefone celular?; (6) Você já sabe como funciona algum deles? Qual ou quais? No total, 73 alunos participaram dessa atividade.

Já a Atividade III foi desenvolvida em agosto de 2012 com as mesmas três turmas do segundo ano do EM já mencionadas. Na oportunidade, foi pedido, aos estudantes, que lessem o texto de divulgação científica "A RMN e suas aplicações atuais" (BONAGAMBA; CAPELLE; AZEVEDO, 2005) - onde RMN é a sigla para ressonância magnética nuclear. Vale frisar que, em outros trabalhos - com objetivos bastante distintos do que foi aqui proposto -, também utilizamos como material de pesquisa informações coletadas nessa atividade.

Concomitantemente à leitura do texto, foi entregue, aos estudantes, um questionário composto pelas seguintes questões: (1) Vocês já ouviram falar em ressonância magnética? O quê? Onde?; (2) Durante a leitura, anote suas dúvidas e faça uma síntese das ideias principais do texto; (3) Pense em alguém a quem você gostaria de contar o que leu. O que você contaria? No total, 53 estudantes entregaram ao professor suas respostas a esse questionário.

$\mathrm{Na}$ semana seguinte, o professor (primeiro autor deste trabalho) realizou uma breve mediação do assunto com as turmas durante duas aulas expositivas pouco dialógicas. Já na terceira semana (duas semanas após a aplicação do primeiro questionário), pediu para que os alunos respondessem a um segundo questionário, o qual era composto por duas questões: (1) Pense na mesma pessoa para quem você contou o que havia lido no texto. Depois da discussão do assunto em sala de aula, você mudaria ou acrescentaria alguma coisa ao que você contaria? O quê?; (2) O que as últimas aulas sobre ressonância magnética acrescentaram ao seu conhecimento? No total, 65 estudantes entregaram, ao professor, suas respostas a esse questionário.

Por fim, destacamos que as três atividades foram pensadas na perspectiva de que a leitura fosse “[...] o ensejo para que os estudantes formulassem suas próprias opiniões sobre o que leram e sobre os interdiscursos que a leitura pode produzir" (ALMEIDA; SOUZA; SILVA, 2006, p. 74). Além disso, vale dizer, ainda, que analisamos aqui apenas respostas dadas à segunda e à quarta questão da Atividade I; à segunda e à quarta questão da Atividade II; à segunda e à terceira questão do primeiro questionário da Atividade III, e à segunda questão do segundo questionário da Atividade III. Justificamos a escolha por analisarmos apenas as respostas dadas a essas questões tendo em vista o fato de que, após realizarmos uma leitura/análise preliminar de todas as respostas dadas a todas as questões, foram sobretudo essas que nos deram evidências para que tecêssemos considerações relacionadas à mobilização pelo estudo de Física. 


\section{Apoio teórico-metodológico e procedimentos de análise}

Tomamos como apoio noções da Análise de Discurso (AD), em sua vertente iniciada, na França, por Michel Pêcheux (1966).

A AD considera que "a linguagem só faz sentido porque se inscreve na história." (ORLANDI, 2005, p. 25), o que equivale a dizer que sempre estamos retomando o já-dito, ou seja, as palavras e os sentidos que já existem. Dessa forma, forja-se a noção de interdiscurso (memória discursiva): todo o conjunto de formulações feitas e já esquecidas que sustentam a possibilidade do dizer e que determinam o que dizemos.

Além disso, uma vez que sempre estamos retomando, repetindo sentidos, Orlandi (2005) distingue três formas de repetição: a empírica (mnemônica), a formal (técnica) e a histórica. A primeira seria o "efeito papagaio", a cópia; a segunda seria outro modo de dizer o mesmo, o "dizer com suas palavras"; já a terceira seria a que desloca, a que historiciza o dizer e o sujeito. Nessa conjuntura, as possibilidades da escola estariam em levar os estudantes a passarem da repetição empírica para a repetição histórica, passando pela repetição formal (ORLANDI, 1998).

Considerar a produção de sentidos na história implica também assumir que há um processo de produção de sentidos que depende das condições de sua produção - entendidas aqui como o contexto imediato, os interlocutores e o contexto sócio-histórico. Consequentemente, se os sentidos produzidos dependem das condições de produção, incluindo as condições históricas, a linguagem é considerada não transparente, isto é, as palavras não portam sentidos.

Vale especificar, ainda, dois elementos que atuam sobre as condições de produção: a capacidade do sujeito de se colocar no lugar do outro visando antecipar os sentidos que suas palavras produziriam - o chamado mecanismo de antecipação (ORLANDI, 2005); e o fato de que o lugar social dos interlocutores, enquanto espaço de representações sociais, é constitutivo da produção de sentidos - as chamadas relações de força -, sendo diferente, por exemplo, falar enquanto professor e enquanto aluno (ORLANDI, 2000, 2005).

Por fim, justificamos a escolha da AD porque seu foco é analisar como ocorre a produção de sentidos, e não quais são os sentidos produzidos.

Quanto aos procedimentos adotados para a análise das informações coletadas, primeiramente, conforme já mencionado, foi realizada, pelo primeiro autor deste trabalho, a leitura/ análise preliminar das respostas dadas a todas as questões. Após a seleção das questões cujas respostas poderiam ser relevantes a este estudo, tomando como aporte a noção de repetição e seus níveis, analisamos de que maneira ocorreu a retomada de sentidos pelos estudantes. Esse procedimento foi realizado pelo primeiro autor e resultou em classificações que, num segundo momento, foram corroboradas pela segunda autora. Justificamos a escolha em utilizar a noção de repetição porque ela torna possível a compreensão do funcionamento das condições de produção propostas aos estudantes. Conforme colocado anteriormente, nas repetições empírica e formal ocorrem, respectivamente, a cópia e pequenas mudanças em relação às condições de produção imediatas (leituras realizadas, falas do professor durante as atividades etc.). Já na repetição histórica, ocorre, também, a retomada de outros sentidos. Assim, ao caracterizarmos que determinadas respostas foram formuladas por meio de repetições empíricas ou formais, o fizemos investigando quais trechos dos textos lidos foram retomados, sendo que a retomada de certos trechos em detrimento de outros indica elementos valorizados pelos estudantes em suas respostas, elementos esses que nos permitiram identificar, num terceiro momento de análise, 
possíveis indícios de mobilização em relação ao estudo da Física e de aspectos que teriam agido como móbiles para a mesma. Etapa esta realizada de maneira independente pelos dois autores.

\section{Análise das informações coletadas na Atividade I}

Apresentamos, a seguir, algumas respostas dadas pelos estudantes do terceiro ano do EM à seguinte questão: "Se você fosse contar a alguém o que leu nesse texto, o que você contaria?" - lembrando que a pergunta se refere ao breve texto que informa, muito sinteticamente, as origens da FQ e qual a sua relevância em termos de aplicações tecnológicas (Anexo A). Ressaltamos que os nomes dos autores das respostas são fictícios, que não foi seguido qualquer critério para escolhê-los - nem sequer o gênero do estudante - e que, em todos os casos, optamos por manter a grafia original da resposta:

Que a quântica e fundamental para os avanços tecnologicos, e sem a quântica não conheceríamos inumeros objetos. [Valdirene]

Contaria que sem a quântica não conbeceríamos inúmeros objetos com os quais lidamos corriqueiramente hoje em dia. [Maurício]

Diria que a teoria quântica é importante para o avanço tecnológico em diversas áreas. [Eva]

Que uma teoria de estudos que pouco conhecemos está praticamente ligada a tudo que usamos hoje em dia. [Enzo]

As respostas de Valdirene e Maurício foram formuladas por meio de repetições empíricas (cópias literais do texto). Maurício copiou o seguinte trecho do texto: "Sem a quântica não conheceríamos inúmeros objetos com os quais lidamos corriqueiramente hoje em dia." Já Valdirene copiou parte desse trecho e também de outro: "A quântica é uma teoria fundamental para os avanços tecnológicos de nosso mundo atual e do vasto conhecimento científico que estamos adquirindo." Já as respostas de Eva e Enzo foram formuladas por meio de repetições formais, ou seja, elas repetem o que o texto diz utilizando, para isso, outras palavras.

Notamos, também, que os estudantes, em geral, parecem ter sido capazes de produzir sentidos coerentes com aqueles que consideramos como sendo os esperados a partir da leitura, a saber: notar a existência de relações entre os desenvolvimentos da teoria quântica e de objetos tecnológicos contemporâneos - 32\% das respostas a essa questão podem ser classificadas como repetições empíricas e 53\% como repetições formais.

Apenas na resposta de uma aluna ficou explícito o relacionamento entre sua história de vida/leituras e a leitura realizada, isto é, uma repetição histórica: "Que a teoria quântica apesar parecer algo complicado e que apenas poucos conseguem entender (os físicos), ela nos cerca e esta presente em nossas vidas e chegamos até depender delas" [Gilmara].

A resposta evidencia que a estudante já havia lido (ou ouvido) que a teoria quântica é uma teoria complicada. Ou seja, a leitura realizada em sala de aula fez com que ela retomasse uma informação que já possuía sobre o assunto, uma vez que, segundo nosso ponto de vista, em nenhum momento, o texto lido em sala de aula dava margem a interpretações como essa.

Quando questionados se gostariam de ter aulas sobre a FQ, 88\% dos estudantes responderam que sim. Esse dado nos causa surpresa, uma vez que a maioria dos alunos do 
EM parece repudiar a Física. Por outro lado, é bem verdade que algumas ressalvas devem ser feitas a esse resultado: a atividade foi desenvolvida com "apenas" 25 alunos e eles podem ter respondido levando em conta o que na opinião deles nós queríamos que eles respondessem, isto é, o mecanismo de antecipação pode ter influenciado suas respostas.

Outra hipótese que provavelmente nos ajuda a explicar esse resultado é considerarmos que a leitura realizada teve influência sobre ele. Nesse sentido, a leitura pode ter agido como móbile do desejo dos estudantes em ter aulas sobre um tópico científico, a FQ, especialmente porque o texto mencionava a importância dessa teoria para o desenvolvimento de alguns objetos tecnológicos contemporâneos.

Entre os estudantes que afirmaram que gostariam de ter aulas sobre FQ, quando questionados "para quê", alguns responderam dizendo que visavam o vestibular; outros afirmaram que gostariam de ampliar seus conhecimentos sobre o assunto, e outros, ainda, afirmaram que o assunto lhes parecia interessante ou importante - o texto, por exemplo, citava a importância dessa teoria para a tecnologia. Apresentamos, a seguir, algumas respostas:

\author{
Sim, para prestar vestibular. [Eva] \\ Sim, para aprender mais sobre a física quântica. [Joseval] \\ Sim porque é muito interessante. [Itamara] \\ Sim, pois aprenderíamos mais sobre coisas importantes e assuntos que podem nos \\ servir depois. [Valdir] \\ Sim, porque sem a quântica não conbeceríamos alguns objetos epassa ser fundamental \\ para o avanço tecnológico moderno. [Naiara]
}

Vale destacar as respostas de Valdir, que evidencia a importância dada pelo estudante a conhecimentos que possuam utilidades práticas, e de Naiara, que destaca, em sua justificativa, a importância da FQ para a tecnologia atual.

\title{
Análise das informações coletadas na Atividade II
}

No que diz respeito aos 73 alunos do segundo ano do EM que participaram da Atividade II, quando questionados sobre o que do breve texto que haviam lido (Anexo A) contariam para alguém, houve predominância de respostas que classificamos como repetições formais (73\%) e de respostas que classificamos como repetições empíricas (19\%). Além disso, 7\% dos estudantes não responderam de maneira clara (foram evasivos, alheios à questão), e apenas um aluno utilizou uma repetição histórica. Em contrapartida, analisando as respostas, notamos que, assim como ocorreu na Atividade I, a grande maioria dos estudantes conseguiu identificar o que parece ser o ponto central do texto: mostrar que há relação entre a FQ e o desenvolvimento de objetos tecnológicos contemporâneos. Apresentamos, a seguir, três respostas, uma classificada como repetição empírica, outra como repetição formal, e outra como repetição histórica:

Eu contaria que a quântica é uma teoria fundamental para os avanços tecnologicos de nosso mundo atual. [Pierre] 
A teoria quântica foi criada para solucionar os problemas tecnológicos e foi ela que ajudon a evoluir muitas coisas como: celular, computador, etc. [Marta]

Contaria que a física quântica, que é uma coisa incrivelmente complexa, esta mais proxima do que nós pensamos, pois, esta presente em diversos aparelhos do nosso cotidiano como, por exemplo, o controle remoto. [Leopoldo]

A primeira resposta é uma repetição empírica, pois, simplesmente, retoma o seguinte trecho do texto lido pelos estudantes: "A quântica é uma teoria fundamental para os avanços tecnológicos de nosso mundo atual e do vasto conhecimento científico que estamos adquirindo." A segunda resposta é uma repetição formal porque fala diretamente sobre o conteúdo do texto lido, mas sem, entretanto, copiar literalmente trechos dele. Já a terceira resposta é uma repetição histórica, pois seu autor foi capaz de relacionar o texto com sua história de vida/ leitura sobre o assunto, pois, certamente, em outra ocasião ele leu (ou ouviu falar) que a FQ era uma teoria complicada.

Vale chamar a atenção para o fato de que os únicos dois estudantes que responderam a essa questão utilizando repetições históricas (um na Atividade I e outro na Atividade II) afirmaram que a FQ é uma teoria complexa, o que sugere que a FQ, ao menos para esses dois jovens, está associada a grande dificuldade - ideia essa que, possivelmente, ou lhes foi anteriormente informada ou resulta de tentativas anteriores de compreender elementos relacionados a essa teoria.

Quando questionados se gostariam de ter aulas sobre FQ, 89\% dos 73 estudantes afirmaram que sim. Esse resultado pode indicar que a leitura realizada agiu como móbile do desejo dos estudantes em ter aulas sobre FQ, possivelmente, porque o texto mostrava a importância dessa teoria para o desenvolvimento de alguns objetos tecnológicos contemporâneos. Nesse sentido, as respostas dos estudantes sugerem que a simples menção da existência de relações entre conteúdos da Física e aspectos do funcionamento de objetos tecnológicos contemporâneos pode funcionar como móbile da mobilização de jovens do EM no que diz respeito ao estudo de tópicos dessa disciplina. Por outro lado, novamente, devemos nos lembrar do possível efeito do mecanismo de antecipação e, nesse caso, também do efeito das relações de força, uma vez que o pesquisador que desenvolveu a atividade era também professor das turmas - o que podia dar, aos estudantes, a ideia de que estavam sendo avaliados.

Apresentamos, a seguir, as respostas de alguns estudantes, lembrando que a questão foi: "Você gostaria de ter aulas sobre a física quântica? Para quê? Por quê?":

Sim. Porque gostaria de saber como funciona. Sempre tive a curiosidade de entender como funciona os aparelhos de CD. [Leopoldo]

Sim, para conhecer como que os objetos do nosso dia-a-dia foi fabricado. [Maira] Sim, para poder aprofundar nossos estudos numa teoria que retrata a formação tecnológica. [Gilberto]

Sim; Pois pelo que percebi a quântica é usada no nosso cotidiano. [Joana] 
Sim, pois com a leitura do texto achei que física quântica parece ser importante no nosso dia a dia e en quero aprender um pouco sobre ela. [Eriberto]

Sim, porque gostaria de saber mais sobre os equipamentos eletrônicos que tanto usamos hoje em dia. [Isabela]

Sim, para conhecer melhor e para que ela serve, ver como que funciona os objetos. [Isaac]

Sim, para entender melhor, o que é e para que serve. [Andressa]

Sim, para eu adquirir mais conhecimento e poder usalo algum dia, por que se estudarmos Fisica quântica, vamos conbecer mais sobre ela e também sera mais usado. [Fabio]

Sim. Para ter mais conhecimento sobre a teoria quântica, pois ela é importante em nossas vidas. Porque esse assunto é bem interessante. [Helena]

Sim, para saber mais sobre os avanços tecnologico e do atual conhecimento cientifico. Isso porque gosto de aprender assuntos ligados a tecnologia. [Edgar]

Essas e outras muitas respostas semelhantes não apresentadas indicam, portanto, que a explicitação de utilidades práticas associadas ao conhecimento ou de possíveis relações entre tópicos da Física e aspectos de objetos tecnológicos contemporâneos pode agir junto a muitos estudantes como móbile da mobilização para o estudo dessa disciplina no EM.

\section{Análise das informações coletadas na Atividade III}

No que diz respeito à Atividade III, que foi desenvolvida com estudantes do segundo ano do EM, analisamos, aqui, algumas respostas que também sugerem o valor atribuído por muitos jovens ao estudo de tópicos cujas utilidades práticas ou possíveis relações com aspectos da cotidianidade - em especial, com a tecnologia - são explicitadas.

$\mathrm{Na}$ segunda questão do primeiro questionário, ao requisitarmos que os estudantes formulassem uma síntese das ideias principais do texto de divulgação científica lido (BONAGAMBA; CAPELLE; AZEVEDO, 2005), obtivemos, entre outras, as seguintes respostas:

Ressonância magnética nuclear (RMN) é um equipamento empregado para diagnóstico médico por imagem. Porém, a RMN é uma técnica que se estende mais além. É empregada hoje como um poderoso instrumento na física, química, medicina, biologia, agricultura é o computador quântico. [...]. [Dagoberto]

O que eu entendi sobre o texto foi que, a ressonância magnética (RMN) não é apenas aquilo que associamos quando ouvimos falar sobre isso, é também usada em áreas como um fator que é o computador quântico que será mais veloz. [...]. [llda] 
A resposta de Dagoberto pode ser classificada como uma repetição empírica, pois o estudante copiou literalmente trechos do texto. Já a resposta de Ilda pode ser classificada como uma repetição formal, uma vez que a estudante procurou parafrasear algumas ideias do texto. Em comum, as duas respostas têm o fato de se remeterem ao seguinte trecho:

Quando se fala em ressonância magnética nuclear (RMN), possivelmente a primeira ideia que vêm à cabeça seja a do equipamento empregado para diagnóstico médico por imagem. A associação se justifica, afinal dezenas de milhões desses exames são feitos por ano no mundo. Mas a RMN é uma técnica que se estende bem além das aplicações médicas. É empregada hoje como um poderoso instrumento na Física, Química, Medicina, Biologia, Agricultura e, mais recentemente, na chamada informação quântica, nova área de pesquisa cujo expoente tecnológico mais popular é o computador quântico, que promete ser impensavelmente mais veloz que seus congêneres atuais. (BONAGAMBA; CAPELLE; AZEVEDO, 2005, p. 40)

Esse parágrafo, cujo intuito parece ser informar que a RMN é aplicada em muitas áreas, e não somente na medicina, foi o mais recorrente nas sínteses formuladas pelos estudantes. Temos três hipóteses complementares para explicar esse fato: trata-se de um trecho simples de ser interpretado; trata-se do parágrafo inicial do texto; e trata-se de um trecho que menciona algumas das aplicações da RMN - o que, nesse caso, novamente sugere que os estudantes valorizam possuir conhecimentos acerca de elementos desse tipo.

Analisando as respostas à terceira questão do primeiro questionário: "Pense em alguém a quem você gostaria de contar o que leu. O que você contaria?”, pudemos notar, novamente, que um dos aspectos mais recorrentes nas respostas foi o de que a RMN é utilizada em muitas áreas do conhecimento. Apresentamos, a seguir, uma resposta desse tipo: "Contaria que Ressonância Magnética Nuclear é mais do que um exame médico. Contaria que é um instrumento poderoso na física, química, medicina, biologia, agricultura e na informação quântica" [Agnaldo].

$\mathrm{Na}$ segunda frase, Agnaldo copiou empiricamente um trecho do texto, enquanto, no início de sua resposta, ele parece ter procurado parafrasear as ideias do texto utilizando "suas palavras" (repetição formal). Todavia, cremos que, mais importante do que classificar a resposta como repetição empírica ou formal, é ressaltar o fato de que a utilização de ambas pressupõe relação direta com o texto. Logo, o que nos parece relevante é notar que trechos do texto são tomados como base para a formulação dessas respostas - o que, como já comentado, pode indicar que os estudantes possuem certa preferência por destacar elementos que dizem respeito a utilidades práticas ou a aspectos relacionados à cotidianidade.

Finalmente, no que diz respeito à segunda questão do segundo questionário: “O que as últimas aulas sobre ressonância magnética acrescentaram ao seu conhecimento?”, notamos que muitos estudantes procuraram destacar, como conhecimento apreendido a partir da Atividade III, elementos que, de alguma forma, ajudam a explicar situações, fenômenos e experiências possíveis de ocorrerem em suas vidas. Em outras palavras: foram pouquíssimas as respostas do tipo: "eu aprendi o que é spin", ou: "eupassei a conhecer o comportamento das particulas". Essa constatação pode indicar certa dificuldade dos alunos em compreender alguns dos conceitos físicos que 
foram discutidos pelo texto e durante a mediação do professor. No entanto, cremos que muito mais do que isso, ela indica que os estudantes valorizam bastante a aquisição de conhecimentos cuja relevância em termos de aplicações ou de utilidades práticas é explicitada. Apresentamos, a seguir, as respostas dadas por alguns alunos, cabendo ressaltar que os grifos são nossos:

A ressonancia magnetica é um tipo de exame que faz c/ a tecnologia e consegue ver nosso corpo inteiro por dentro sem prejudicar a saúde. [Cintia]

O raio x ele é um exame que ele não pode ser feito varias vezpois faz mal a saude a ultrassom e muito mais diferente pois ele detecta a imagem pelo som. [Gisele]

Conhecimento, pois até ler os textos eu não sabia que aquelas máquinas que via em filmes e novelas, tinha esse nome e essas qualidades. [Vivian]

Agora eu sei como funciona, que com a ressonância magnética conseguimos ver melhor dentro do nosso corpo. E ela também pode ser feita várias vezes, pois a radiação é baixa. [Mario]

O raio x é um exame que não pode ser feito varias vezes ao ano pois faz mal a saude, o ultrassom é diferente pois ele detecta a imagem pelo som, $O$ celular ainda é uma duvida se faz mal a saude, a bussola que tem um imã e sempre aponta para o norte por causa do magnetismo da Terra. [Marina]

Deupara conbecer um pouco mais sobre o assunto pelo qual eu não sabia muito, para que serve e para que é muito utilizada boje em dia na vida da sociedade. [Agda]

Acrescentou umas informações que não tinha como saber que o raio x não pode fazer com tanta frequencia. [Ronan]

Eu tomei conbecimento de como varios exames é feito, agora saberei como funciona o que pode ser men futuro exame. Aprendi que o celular, ninguem sabe se far mal ou bem pra saude, aprendi tambem que uma bussula sempre aponta pra norte por causa do magnetismo da terra. [Silvio]

Há a possibilidade de que os estudantes que escreveram as respostas acima tenham produzido alguns sentidos sobre o que é spin, sobre o comportamento das partículas, enfim, sobre assuntos discutidos pelo texto e na mediação do professor, embora esses conceitos não tenham sido explicitados em suas respostas. Entretanto, o que suas respostas parecem evidenciar é que eles deram destaque a aspectos que foram explicitamente relacionados a possíveis situações da sua cotidianidade, em detrimento de aspectos discutidos apenas teoricamente, ainda que estes sejam, evidentemente, também muito importantes. 
Corrobora essa consideração o fato de que durante a mediação do professor foi possível notar maior participação dos estudantes em discussões conceituais que fossem associadas a aspectos relacionados às suas vidas - como, por exemplo, as discussões sobre as energias associadas a cada faixa de radiação do espectro eletromagnético (radiofrequência, microondas, ultravioleta etc.); e em discussões relacionadas a objetos tecnológicos contemporâneos, como sobre algumas diferenças entre técnicas que propiciam a produção de imagens (como raios-X, ultrassom e RMN); e sobre questões de natureza prática em relação à realização do exame de ressonância magnética (como não poder entrar na sala do exame com objetos metálicos etc.).

Ressaltamos, ainda, que diversos estudantes apontaram, como conhecimento apreendido a partir da Atividade III, a possibilidade de compreenderem aspectos do funcionamento de objetos tecnológicos contemporâneos, tais como: os aparelhos de raios-X, de ultrassom e de ressonância magnética, os telefones celulares e as bússolas - os grifos, nas respostas acima, embasam essa consideração. Dessa forma, assumindo a hipótese de que foram destacados, nas respostas, os elementos que mais lhes marcaram, que mais lhes mobilizaram, consideramos que a explicitação de possíveis relações da Física com aspectos de objetos tecnológicos contemporâneos pode agir como móbile da mobilização pelo estudo dessa disciplina.

\section{Considerações finais}

As análises realizadas neste trabalho sugerem que explicitar utilidades práticas e/ou aspectos da cotidianidade associados à Física pode mobilizar os estudantes do Ensino Médio pelo estudo dessa disciplina. Mais especificamente, tendo em vista a grande presença atual da tecnologia na vida de boa parte da população brasileira, as análises sugerem que um dos possíveis móbiles da mobilização em relação ao estudo da Física pode ser a explicitação de relações entre os conteúdos formais dessa disciplina e aspectos associados à produção e ao funcionamento de objetos tecnológicos contemporâneos, tais como: o rádio, o telefone, o computador, o aparelho de raios-X e o aparelho de ressonância magnética. Por outro lado, talvez também seja necessário tomar o cuidado de não apresentar a tecnologia como uma mera aplicação da ciência, reforçando ainda mais essa crença já culturalmente dominante (GARDNER, 1999); e de colocar ciência e tecnologia como a solução de todos os problemas, numa postura salvacionista (AULER ; DELIZOICOV, 2001).

Embora acreditemos que essa estratégia possa ser uma forma de minimizar a baixa mobilização dos estudantes em relação a parte das atividades sugeridas pelos professores na escola, cremos que, paralelamente a isso, talvez seja necessário buscar maneiras de desconstruir a ideia socialmente dominante de que todo conhecimento deve ser claramente útil para determinadas finalidades. Nesse sentido, parece-nos interessante investir na ideia do conhecimento enquanto cultura, pensando sua aquisição como autodesenvolvimento, como ampliação de horizontes. 


\section{Agradecimentos}

André Coelho da Silva agradece à Fundação de Amparo à Pesquisa do Estado de São Paulo (FAPESP) pela Bolsa de Mestrado - Processo 2.012/03451-0. Maria José P. M. de Almeida agradece ao Conselho Nacional de Desenvolvimento Científico e Tecnológico (CNPq) pela Bolsa de Produtividade em Pesquisa - Processo 307.889/2013-0. Ambos agradecem aos árbitros pelas valiosas contribuições a este artigo.

\section{Referências}

ALMEIDA, M. J. P. M.; SOUZA, S. C.; SILVA, H. C. Perguntas, respostas e comentários dos estudantes como estratégia na produção de sentidos em sala de aula. In: NARDI, R.; ALMEIDA, M. J. P. M. (Org.). Analogias, leituras e modelos no ensino de ciência: a sala de aula em estudo. São Paulo: Escrituras, 2006. p. 61-75.

AULER, D.; DELIZOICOV, D. Alfabetização científico-tecnológica para quê? Ensaio: Pesquisa em Educação em Ciências, Belo Horizonte, v. 3, n. 1, p. 1-13, 2001. Disponível em: <http://www.portal.fae.ufmg.br/seer/index.php/ensaio/article/viewFile/44/203>. Acesso em: 18 jul. 2014.

BONAGAMBA, T. J.; CAPELLE, K. W.; AZEVEDO, E. R. A RMN e suas aplicações atuais. Ciência Hoje, Rio de Janeiro, v. 37, n. 221, p. 40-48, 2005. Disponível em: <http:/ / cienciahoje.uol.com.br/revista-ch/revista-ch-2005/221/a-rmn-e-suas-aplicacoes-atuais>. Acesso em: 06 fev. 2013.

CHARLOT, B. Da relação com o saber: elementos para uma teoria. Porto Alegre: Artes Médicas Sul, 2000.

DAYRELL, J. A escola como espaço sócio-cultural. In: . (Org.). Múltiplos olhares sobre educação e cultura. Belo Horizonte: UFMG, 1996. p. 136-161.

DIAS, A. C. G.; BARLETTE, V. E.; MARTINS, C. A. G. A opinião de alunos sobre as aulas de eletricidade: uma reflexão sobre fatores intervenientes na aprendizagem. Experiências em Ensino de Ciências, Cuiabá, v. 4, n. 1, p. 107-117, 2009. Disponível em: < http:// if.ufmt.br/eenci/artigos/Artigo_ID76/v4_n1_a2009.pdf>. Acesso em: 06 fev. 2013.

FOUREZ, G. Crise no ensino de ciências? Investigações em Ensino de Ciências, Porto Alegre, v. 8, n. 2, p. 109-123, 2003. Disponível em: < http://www.if.ufrgs.br/ienci/artigos/ Artigo_ID99/v8_n2_a2003.pdf>. Acesso em: 06 fev. 2013.

GARDNER, P. L. The representation of science-technology relationships in Canadian physics textbooks. International Journal of Science Education, London, v. 21, n. 3, p. 329-347, 1999. Disponível em: <http://dx.doi.org/ 10.1080/095006999290732>. Acesso em: 06 fev. 2013.

GRANGER, G. G. A ciência e as ciências. São Paulo: Editora da Unesp, 1994. 
HALL, S. A centralidade da cultura: notas sobre as revoluções culturais do nosso tempo. Educação e Realidade, Porto Alegre, v. 22, n. 2, p. 15-46, 1997.

LIMA, M. F. C.; RAPPOPORT, T. A sala de aula, o ensino de física e as novas tecnologias: a professora Magali F. C. Lima entrevista a professora Tatiana Rappoport. Ciência em Tela, Rio de Janeiro, v. 2, n. 1, p. 1-8, 2009. Disponível em: < http://www.cienciaemtela.nutes.ufrj. br/artigos/0109entrevista.pdf>. Acesso em: 06 fev. 2013.

MICHAELIS: moderno dicionário da língua portuguesa. 2009. Disponível em: $<$ http://michaelis.uol.com.br/moderno/portugues/index.php?lingua=portuguesportugues\&palavra=aparelho $>$. Acesso em: 11 fev. 2015.

NASCIMENTO, S. S.; SANTOS, R.; NIGRI, E. Alfabetização científica e tecnológica e a interação com os objetos técnicos. Caderno Brasileiro de Ensino de Física, Florianópolis, v. 23, n. 1, p. 53-67, 2006. Disponível em: <http://www.periodicos.ufsc.br/index.php/fisica/ article/view/6290/5823>. Acesso em: 06 fev. 2013.

ORLANDI, E. P. Análise de discurso: princípios \& procedimentos. 6. ed. Campinas: Pontes, 2005.

Discurso e leitura. 5. ed. Campinas: Editora da UNICAMP, 2000.

. Paráfrase e polissemia: a fluidez nos limites do simbólico. Rua, v. 4, p. 9-19, 1998.

PÊCHEUX, M. (Com o pseudônimo de Thomas Herbert). Reflexions sur la situation théorique des sciences sociales et, spécialement, de la psychologie sociale. Cahiers pour l'analyse, Paris, v. 2, p. 174-203, 1966. < http://cahiers.kingston.ac.uk/pdf/cpa2.6.herbert. pdf>. Acesso em: 12 fev. 2015.

PEREIRA, A. P.; OSTERMANN, F. Sobre o ensino de física moderna e contemporânea: uma revisão da produção acadêmica recente. Investigações em Ensino de Ciências, Porto Alegre, v. 14, n. 3, 2009. Disponível em: <http://www.if.ufrgs.br/ienci/artigos/Artigo_ ID224/v14_n3_a2009.pdf>. Acesso em: 01 jul. 2014.

SILVA, A. C.; ALMEIDA, M. J. P. M. Física quântica no ensino médio: o que dizem as pesquisas. Caderno Brasileiro de Ensino de Física, Florianópolis, v. 28, n. 3, p. 624-652, 2011. Disponível em: <https://periodicos.ufsc.br/index.php/fisica/article/view/21757941.2011v28n3p624/20255>. Acesso em: 01 jul. 2014.

VARGAS, M. Técnica, tecnologia e ciência. Revista Educação \& Tecnologia, Curitiba, n. 6, p. 178-183, 2003. Disponível em: <http://revistas.utfpr.edu.br/pb/index.php/revedutecct/article/viewFile/1084/687>. Acesso em: 06 fev. 2013.

ZANETIC, J. Física também é cultura. 1989. 252 f. Tese (Doutorado em Educação) Faculdade de Educação, Universidade de São Paulo, São Paulo, 1989. 
Anexo A. Texto utilizado durante as Atividades I e II

A teoria quântica surgiu da tentativa de se compreenderem os problemas de interação da radiação
com a matéria e solucionar alguns desses problemas. Vários textos dizem que o primeiro passo no
desenvolvimento dessa teoria foi um trabalho de Max Planck em 1900.
- Mas para que ela serve, qual é a sua relevância para a nossa vida?
A quântica é uma teoria fundamental para os avanços tecnológicos de nosso mundo atual e do vasto
conhecimento científico que estamos adquirindo. Grandes avanços práticos e teóricos em áreas
como astronomia, medicina, biologia, química e física são frutos de sua aplicação. Seus conceitos
causaram uma revolução na forma como entendemos o universo, mostrando que o comportamento
da matéria a nível atômico não obedece a regras bem estabelecidas de nosso mundo macroscópico.
Sem a quântica não conheceríamos inúmeros objetos com os quais lidamos corriqueiramente hoje
em dia. Só para se ter uma ideia, podemos mencionar o nosso aparelho de CD, o controle remoto
de nossas TVs, os aparelhos de ressonância magnética em hospitais, os telefones celulares, os
laseres, a genética molecular e, até mesmo, o microcomputador. Todos os dispositivos eletrônicos
usados nos equipamentos da chamada high-tech (alta-tecnologia) só puderam ser projetados porque
conhecemos a mecânica quântica.
Texto adaptado a partir de:
CALDEIRA, A. A física quântica: o que é, e para que serve. Com Ciência: Revista Eletrônica de
Jornalismo Científico, n. 20,2001 . Disponível em: <http://www.comciencia.br/reportagens/
framereport.htm>. Acesso em: 09 fev. 2015 .
DE GROOTE, J. J. A teoria quântica depois de Planck. Com Ciência: Revista Eletrônica de
Jornalismo Científico, n. 20, 2001. Disponível em: <http://www.comciencia.br/reportagens/
framereport.htm>. Acesso em: 09 fev. 2015 .
MARTINS, R. A. A física no final do século XIX: modelos em crise. Com Ciência: Revista
Eletrônica de Jornalismo Científico, n. 20 , 2001 . Disponível em: <http://www.comciencia.br/
reportagens/framereport.htm>. Acesso em: 09 fev. 2015 .

Artigo recebido em 21/08/13. Aceito em 16/07/14 